\title{
COAXIAL HIGHER-ORDER MODE DAMPER EMPLOYING A HIGH-PASS FILTER
}

\author{
$Y$. W. Kang and $X$. Jiang \\ Advanced Photon Source, Argonne National Laboratory \\ 9700 South Cass Avenue, Argonne, Illinois 60439 USA
}

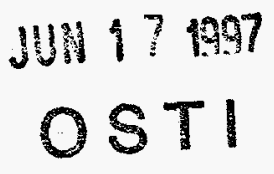

\section{Abstract}

Two different types of coaxial higher-order mode (HOM) dampers have been investigated for the Advanced Photon Source (APS) storage ring cavities: e-probe dampers and $h$-loop dampers. Realization of the h-loop dampers has been difficult because the loop antenna couples not only to the HOMs but also to the accelerating mode and results in loss of $Q$ at the fundamental frequency. Previously, a first-order fundamental rejection filter was tested with unsatisfactory rejection characteristics. This problem can be overcome by using a higher-order high-pass filter between the loop and the matched load. Prototype dampers have been fabricated and tested in a storage ring single-cell cavity and the damping characteristic was analyzed.

\section{NTRODUCTION}

The single-cell cavities being used in the APS storage ring are optimized spherical type cavities whose fundamental accelerating mode frequency is $352 \mathrm{MHz}$. Each cavity frequency is adjusted with a mechanical plunger tuner. The cavities are manufactured to have a slight elongation with an increment in the lengths for a staggered frequency characteristic at the HOMs. The effect of the staggering cavity HOM frequencies was studied and the instability growth rates and the deQing requirement on higher-order modes of the APS storage ring were reported $[1,2]$.

For the APS storage ring cavities, dampers with Eprobe and $\mathrm{H}$-loop couplers have been developed to damp HOMs in $352-\mathrm{MHz}$ single-cell cavities for the storage ring of the APS. The H-loop dampers employ high-pass filters for fundamental frequency rejection. The fundamental frequency rejection filter has a very steep rejection response and minimum deQing at the fundamental frequency. A similar H-loop coupled coaxial damper with a higher-order high-pass filter has been used for $433-\mathrm{MHz}$ cavities of an accelerator for free-electron laser application [3].

For HOM dampers. broadband damping and less fundamenta! mode damping are important. In the waveguide dampers. the fundamental frequency rejection is achieved by the cutoff characteristic of the waveguide. For coaxial HOM dampers. a proper fundamental frequency rejection scheme must be implemented. E-probe dampers can be used in the cavity equatorial plane without the rejection filter, since the radial component of the $\mathrm{TM}_{01}$-like electric rield is zero in the midplane. Since the H-loop dampers are used in the equatorial plane of the cavity. the loop plane must be perpendicular to the fundamental mode $\mathrm{H}$-field to couple with the many transverse magnetic HOMs, and a fundamental frequency rejection filter is needed. Previously, H-loop dampers with a half-wavelength short stub in parallel or a quarter-wavelength short stub in series have been tested [4]. The rejection characteristics of the single stub designs were poor and also rejected some HOM frequencies around the even and odd multiples of fundamental frequency. Since the poor rejection characteristic increased the fundamental mode power loss, a damper with a better rejection filter has been investigated.

\section{LOOP COUPLED DAMPER}

Figure 1 shows the loop coupling coaxial damper assembly. The H-loops are used in the cavity midplane. The loop plane is perpendicular to the $\mathrm{TM}_{01}$ mode $\mathrm{H}$-field. Two dampers are used to damp the dipole modes. Both the size of the loop and the location in the cavity determine the coupling to specific mode fields and thus the damping ratio.

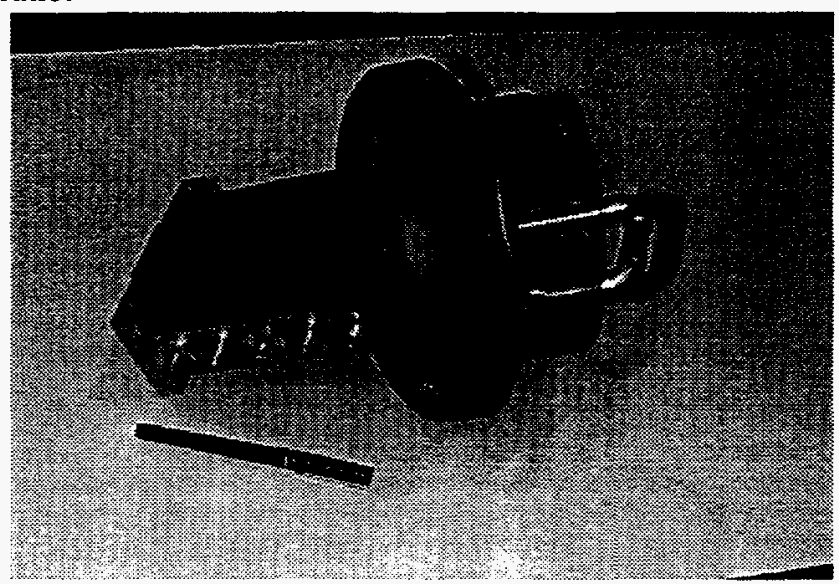

Figure 1: H-loop type coaxial damper with high-pass filter.

\subsection{Coupling Loop}

Two H-loop type dampers are used on the 6" ports in the cavity midplane with an angular separation of $90^{\circ}$. The loop plane in this position strongly couples to the $\mathrm{TM}_{01}$ mode field. Therefore. the measured input impedance of the coupling loop shows low impedance values for overcoupling. The coupling loop is made of 0.5 "diameter copper tube.

Figure 2 shows the measured input impedance of the damper coupling loop of various sizes. The low impedance of the loop at a resonant frequency shows that the mode of the frequency can be damped by the resistive termination whose resistance value is greater than the input resistance. The different coupling gives varied damping at other mode frequencies. Greater loop sizes have lower loop input

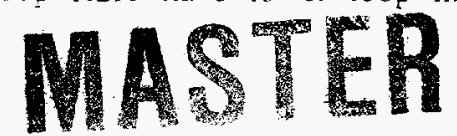

The submitted manuscript has been created by the University of Chicago as Operator of Argonne Vational Luboratory 1 "Argonne”, wnde: Contract No. W-31-109-ENG-38 with the U.S. Department of Energy. The U.S. Government retains for itself, and others acting on its behalf, a paid-up. nonexilusive. irtevocable worldwide license in silid

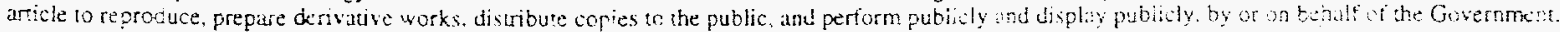




\section{DISCLAIMER}

This report was prepared as an account of work sponsored by an agency of the United States Government. Neither the United States Government nor any agency thereof, nor any of their employees, make any warranty, express or implied, or assumes any legal liability or responsibility for the accuracy, completeness, or usefulness of any information, apparatus, product, or process disclosed, or represents that its use would not infringe privately owned rights. Reference herein to any specific commercial product, process, or service by trade name, trademark, manufacturer, or otherwise does not necessarily constitute or imply its endorsement, recommendation, or favoring by the United States Government or any agency thereof. The views and opinions of authors expressed herein do not necessarily state or reflect those of the United States Government or any agency thereof. 


\section{DISCLADMER}

Portions of this docament may be illegible in electronic image products. Images are produced from the best available original docoment. 
resistance and provide greater damping due to greater over-coupling in general. However, the damping of the higher frequency HOMs are sensitive to the loop sizes, since the loop inductance may approach or exceed the quarter wavelength at these frequencies. For the higher frequency HOMs, the high loop input impedance may result in under-coupling which gives poor damping. For the low toop impedance, the fundamental frequency rejection filter needs to have low input resistance in order to have smaller fundamental frequency damping. From the measurement, it can be seen that $50-\Omega$ load resistance is adequate for damping the HOMs.

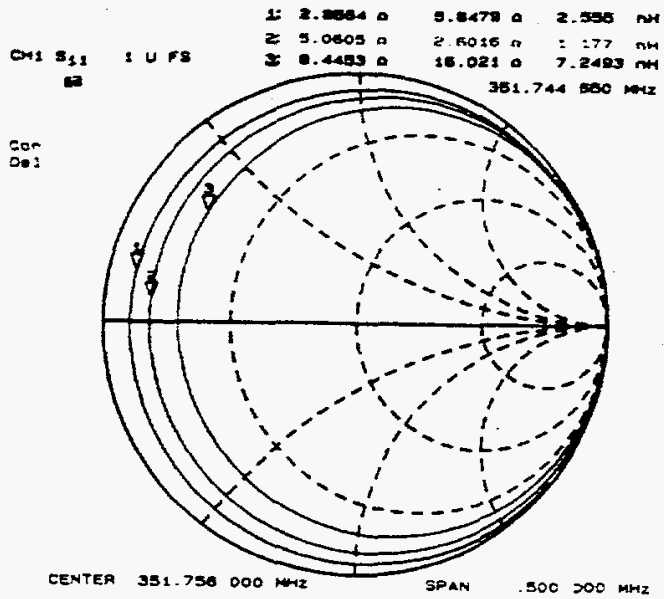

Figure 2: Input impedance of the coupling loop of various sizes: (1) 5 inch $^{2}$, (2) 3.7 inch $^{2}$, (3) 2.4 inch $^{2}$.

\subsection{High-Pass Filter}

A fundamental frequency rejection is necessary to minimize the loss of the accelerating field using a bandstop or a high-pass filter. For the APS, an H-loop damper design employing a high-pass filter has been investigated to obtain a good fundamental frequency rejection. For the rejection at $352 \mathrm{MHz}$ in a compact package, a 9-th order coaxial Chebyshev-type filter was chosen [5]. The filter has a $0.5-\mathrm{dB}$ pass-band ripple and $70 \mathrm{~dB}$ rejection at 350 $\mathrm{MHz}$, and a corner frequency of $480 \mathrm{MHz}$. Figure 3 shows the measured frequency characteristics of the high-pass filter. This frequency response is very close to the predicted response from calculation. The construction of the filter is shown in Figure 4. All coaxial transmission line sections have a 1 " outer diameter and a $50-\Omega$ characteristic impedance. The crossed tuning stubs support the center conductor of the filter which consists of four capacitors and five copper pieces. The capacitors are made with kapton dielectric and copper sheets around the dielectric. Sliding shorts are used on the stubs to adjust the stub inductances for the desired frequency response. The input and output impedances are chosen to be $50 \Omega$ for simplified measurement and near optimum Q-factor of the transmission lines. The circuit component values of the filter elements are shown in Table 1.

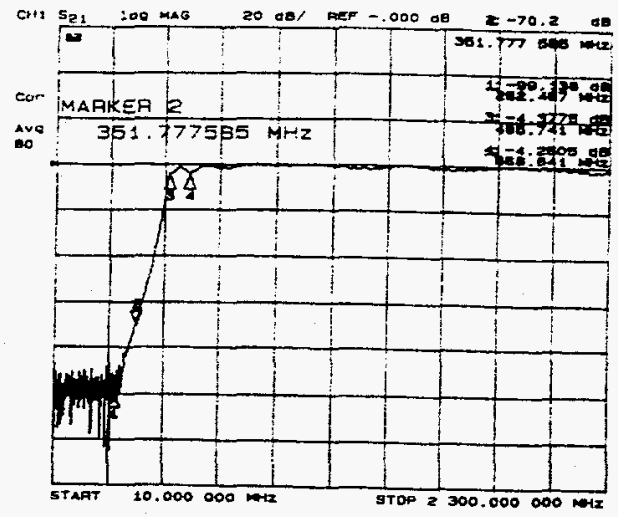

Figure 3: Measured frequency response of the filter.

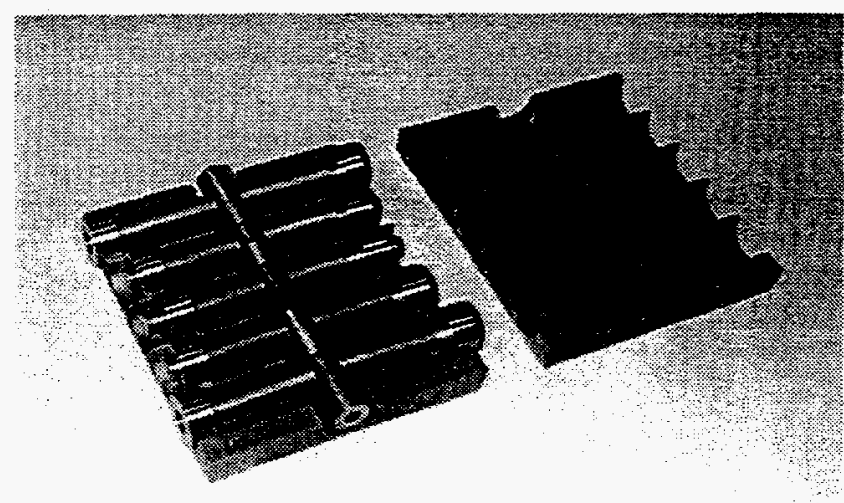

Figure 4: Coaxial high-pass filter structure.

\subsection{Rf Absorber}

For the dampers, matched load terminations are used. The load must be able to dissipate a certain amount of power with good vacuum properties if no vacuum barrier is used. Water cooling is needed for the high-power couplers and the load. Since reliable water cooling with metal tubing always forms a short circuit for the rf signal, a lossy dielectric-type load is desirable unless a noninterfering water passage is provided. Therefore, in an E-probe damper with water cooling through the center conductor of the coaxial structures, an aluminum nitride (AlN) ceramic absorber was used. However, in the H-loop damper design, the center conductors of the coaxial stubs can provide water passage, and so compact broadband, high power resistor-type of loads can be used. This type of load is made of a carbon resistor on a beryllium oxide $(\mathrm{BeO})$ ceramic substrate. The mechanical and electrical properties of this termination are shown in Table 1. The measured frequency characteristic of the coaxial termination is shown in Figure 5.

Table 1: Termination Specification

\begin{tabular}{|l|l|}
\hline Impedance & $50 \Omega$ nominal \\
\hline Power handling capability & $250 \mathrm{~W} \mathrm{CW}, 1000 \mathrm{~W}$ peak \\
\hline Thermal resistance & $0.3^{\circ} \mathrm{C} / \mathrm{W}$ \\
\hline
\end{tabular}




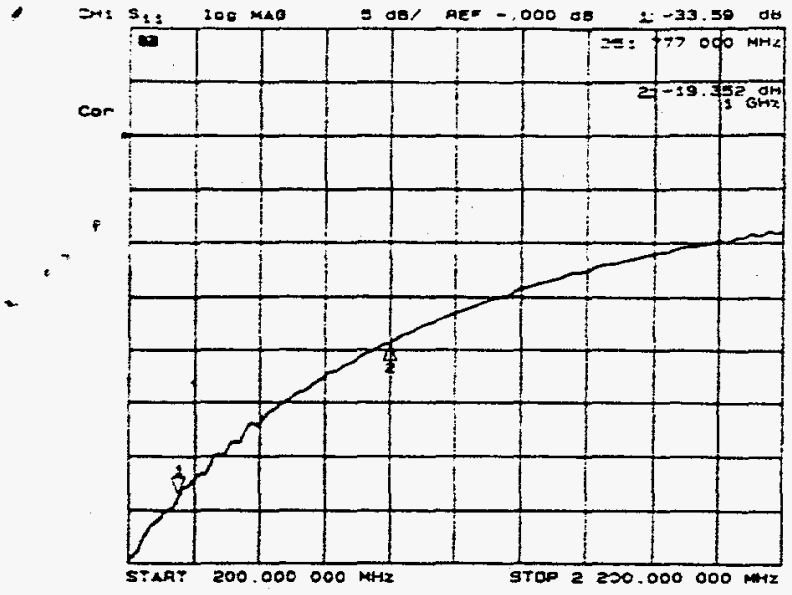

Figure 5: Frequency response of the $50-\Omega$ resistive termination.

\section{MEASUREMENT}

Each cavity will have two E-probe dampers and two H-loop dampers when the dampers are ready. In the present measurements, only two H-loop dampers with 9-th order Chebyshev high-pass filters have been used. The measured deQing ratios are shown in Table 2. The coupling loops have an area of $3.7 \mathrm{in}^{2}$. The listed modes are the most dangerous HOMs in the single-cell cavity being used in the APS and can cause beam instability. Q-factors are measured using a vector network analyzer and compared with the computed results. In mode designation, 0 and 1 denote the monopole modes and the dipole modes, respectively. $\mathrm{M}$ and $\mathrm{E}$ denote the boundary conditions with magnetic and electric walls in the cavity equatorial plane, respectively. The result shows that most dipole modes are damped effectively; the fundamental mode is damped little while the first dipole mode is damped significantly. Note that some monopole modes can also be damped with the $\mathrm{H}$-loop dampers since the loop is offset from the cavity midplane.

Table 2: Measured Q-factors for the Higher-Order Modes with Two Dampers with High-Pass Filters

\begin{tabular}{|c|c|c|c|}
\hline Mode & $\begin{array}{c}\text { Frequency } \\
(\mathrm{MHz})\end{array}$ & Unloaded Q & Damped Q \\
\hline \hline $0-\mathrm{E}-\mathrm{1}$ & 351.7 & 48.000 & 44,270 \\
\hline $0-\mathrm{M}-1$ & 535.7 & 43.610 & 306 \\
\hline $0-\mathrm{E}-1$ & 582.3 & 60.200 & 302 \\
\hline $0-\mathrm{E}-2$ & 742.6 & 57.760 & 455 \\
\hline $1-\mathrm{M}-2$ & 758.4 & 44.370 & 757 \\
\hline $0-\mathrm{E}-3$ & 916.6 & 82.920 & 688 \\
\hline $1-\mathrm{E}-3$ & 952.1 & 46.470 & 1,113 \\
\hline $1-\mathrm{M}-1$ & 1014.8 & 31.800 & 8,022 \\
\hline $1-\mathrm{E}-5$ & 1147.2 & 42.710 & 5,262 \\
\hline $0-\mathrm{E}-6$ & 1511.5 & 89.690 & 1,566 \\
\hline
\end{tabular}

\section{DISCUSSION}

For the coaxial HOM dampers, it was desired to have lower deQing at the fundamental frequency while having higher damping at other harmful HOMs. The fundamental mode deQing is due to the finite $Q$ of the input coupler and the high-pass filter at the frequency. Although the rejection ratio of the filter alone is measured to be $-70 \mathrm{~dB}$ which provides almost no power transmission, fundamental deQing still exists. Since the filter characteristic is measured for a $50-\Omega$ system, the low resistance of the loop cannot have a high rejection ratio. The intrinsic resistance of the copper parts in the loop and the filter input contribute to a loss that is not negligible. The next step is brazing an annular alumina ceramic window between the coupling loop and the filter input in order to eliminate the exposure of the filter circuit to the vacuum. High power testing of the dampers will be performed with the ceramic window.

The measurements show that the coaxial dampers can provide good performance for the cavities without provision for special waveguide-type damper ports. The measured fundamental frequency deQing factor is about $9 \%$ with two dampers. This is a great improvement from previous studies and may be one of the lowest values with the HOM damping. The dampers are compact and will dissipate low power at the fundamental frequency. Compared with the deQing requirement of the HOMs in the APS storage ring, the results of measurements show that many HOMs can be damped successfully with the coaxial dampers. This result is promising for use of the design in the storage ring of the APS.

\section{ACKNOWLEDGMENT}

The authors thank Arther Vetter of Boeing Defense and Space Group for helpful information on the damper with high-pass filter. The authors also thank W. Yoder and D. Bromberek for their effort in prototype fabrication and measurement of the dampers. This work was supported by the U.S. Department of Energy, Office of Basic Energy Sciences, under Contract No. W-31-109-ENG-38.

\section{REFERENCES}

[1] L. Emery, "Coupled-Bunch Instabilities in the APS Ring," Proc. of the 1991 Particle Accelerator Conference, pp. 1713-1715, 1991.

[2] L. Emery, "Required Cavity HOM deQing Caleulated from Probability Estimates of Coupled Bunch Instabilities in the APS Ring." Proc. of the 1993 Particle Accelerator Conference. pp. 3360-3362, 1993.

[3] A. M. Vetter. T. L. Buller, and T. D. Hayward. D. R. Smith, and V. S. Starkovich. "APLE Accelerator Prototype Cavity Fabrication and Low Power Tests." Proc. of the 1993 Particle Accelerator Conference, pp. 1075-1077, 1993.

[4] P. J. Matthews. Y. W. Kang, and R. L. Kustom. "Storage Ring Cavity Higher-Order Mode Dampers for the Advanced Photon Source." Proc. of the 1995 Particle Accelerator Conference. pp. 1684-1886. 1995

[5] G. Mathei. L. Young. and E. M. T. Jones. Microucle Filters, Impedunce- Matching. Networks, and Coupling Structures. Artech House. 1980. 